\title{
Constellation work principles, resonance phenomena, and shamanism in South Africa
}

\begin{abstract}
Claude-Hélène Mayer and Adriaan Viviers
Abstract

The pioneering work of Bert Hellinger in 'Familien-Stellen' (constellation work) started in the 1970s in KwaZulu-Natal, South Africa. It was the beginning of the international therapeutic movement, which is contemporarily based on different theoretical and therapeutic intervention approaches. Since then, constellation work has received recognition in Europe, followed by the United States, Australia, and later Asia. Scientists and practitioners have contributed to its development. However, constellation work as a counselling and therapeutic intervention in African contexts has hardly been recognised and explored. This article explores principles and resonance phenomena in constellation work and their interlinkages with shamanism as a cross-cultural counselling intervention method. The study uses an empirical in-depth qualitative research approach within the phenomenological paradigm and semi-structured interviews with six constellation facilitators and participative observation. Findings provide insight into principles of constellation work in South Africa, explanations of the resonances and the knowing field phenomenon, the connection of constellation work and shamanism, as well as context-specific future directions. Thus, it provides theoretical and practical recommendations in African contexts and beyond.
\end{abstract}

\section{Keywords}

Constellation work, emic views, family constellators, qualitative research, resonance phenomena, shamanism, South Africa

\section{Introduction}

Since 1994, South Africa has undergone tremendous change, becoming a highly complex, multicultural society with changing social identities, perceptions of diverse cultural groups, and definitions of diversity criteria. Race, gender inequalities, and other diversity categories still exist (Chugh \& Brief, 2008; Lyubomirsky, 2013), leading to a fragmented and controversial society (Mayer \& Viviers, 2014a) struggling with external and internal categories of apartheid (Mayer, 2005). Across cultural groups, there is a longing for healing the wounds of the past (Steyn, 2001). Various collective healing processes are promoted (Leildé, 2008; Lund, 2003) through narration (Young, 2004), community (Gobodo-Madikizela, 2002), and reconciliation work (De la Rey \& Owens, 1998) to reconstruct a peaceful society (Allen \& Allen, 2000) by reviewing concepts of perpetration and oppression (Swartz, 1996). Within the South African society, indigenous healing is en vogue (Mpofu, Peltzer, \& Bojuwoye, 2011), and numerous South Africans consult traditional healers (Ross, 2007) and use natural substances, prayer, and various rituals to support mental and physical well-being. Research shows that for medical and psychological healing, constellation work (CW) is used in different societies and cultural groups (Mason Boring, 2004; Van Kampenhout, 2003, 2008); however, hardly any study can be found on CW in South African contexts (Mayer \& Viviers, in press). At the same time, psychological discourses aim at combining traditional and psychological healing and therapies (Moodley \& West, 2005) for developing mental health and well-being (Berg, 2003). 
$\mathrm{CW}$ is an intervention method that aims at salutogenesis and the development of mental health and overall well-being (Mayer \& Hausner, 2015) by integrating elements of family systems therapy, existential phenomenology, and ancestral belief (Cohen, 2006). In practical CW, these elements are integrated pragmatically. A commonly accepted theoretical, empirically based framework has not yet been developed to integrate these elements and to describe their interrelationships and forms of integration in CW (Stresius, 2006). CW has rather been practically developed through an international, interdisciplinary movement which started with the pioneering work of Bert Hellinger in the 1970s. CW has gained popularity not only across Europe (Hunger, Bornhäuser, Link, Schweitzer, \& Weinhold, 2014; Stiefel, Harris, \& Zollmann, 2002) but also in the United States (Cohen, 2006; Georgiadou, 2012), Australia (Rogers, 2010), and Asia (Weng, 1997). Recent approaches aim at integrating shamanic healing principles (Payne, 2005; Van Kampenhout, 2003), indigenous knowledge (Mason Boring, 2004), neurobiology (Peyton, 2015), trauma healing (Levine, 2005), nature and earth constellations (Mason Boring \& Sloan, 2013), or Kabbalist principles (Schusterman, 2003) into CW. CW has also found access to the field of organisational learning and change management processes (Birkenkrahe, 2008; Peterson, 2005; Roevens, 2008), and its approach has been broadened on the foundation of Hellinger's pioneering work. Lynch and Tucker (2005) argue that since the first approaches of CW by Hellinger, a new generation of practitioners has developed and $\mathrm{CW}$ has undergone changes in perspectives and practices that are diverse and multiple. This study defines $\mathrm{CW}$ as an intervention method that is based on multiple practical and theoretical approaches, which have been developed during the past decades. In the following section, the foundational principles of $\mathrm{CW}$ will be introduced and the theoretical background of $\mathrm{CW}$, resonance theories, and shamanism will be explored. Findings will be presented with regard to the South African culture-specific context.

\section{The process in CW}

Constellation facilitators can work with $\mathrm{CW}$ in single therapy sessions as well as in group processes. This study focuses on $\mathrm{CW}$ in group processes, which follow certain defined principles. $\mathrm{CW}$ is an approach to resolve personal, family, professional, or organisational issues by mapping a present reality (Livotov, 2007). The client defines his or her problem or question in dialogue with the $\mathrm{CW}$ facilitator, while the group is listening to the interaction. After the definition of the problem, the client asks group members to represent (pre-defined) individuals, aims, or objects that are systemically involved in the problem (Cohen, 2008). The representatives are placed in a certain physical position by the client, and their constellation towards each other becomes obvious and conscious (Cohen, 2004). Once the representatives are in place, they are observed and asked to tune in with the resonance (Livotov, 2007). They are then asked how they feel and what they perceive and thereby represent a living map (Livotov, 2007, p. 1). The facilitator might ask questions, observe the client, who observes the representatives, and sometimes introduce movements to the representatives. The aim is to create a solution for the problem by working with the representatives through the systemic patterns and dimensions towards a position within the system in which they feel mostly comfortable. ${ }^{1}$

\section{Principles in CW}

Principles in $\mathrm{CW}$ are defined as repeating patterns that are visible during different constellations (Birkenkrahe, 2008, p. 16). Principles are seen as underlying patterns of representative perception in CW (Podirsky \& Würtenberger, 2011) and are strongly connected to phenomena of intuition and knowledge (Mayer, 2015).CW was originally based on three principles called 'orders of love' (Hellinger, Weber, \& Beaumont,1998) and was developed through theoretical assumptions and in practical constellation sessions. Different authors (e.g., Green, 2008; McQuillin \& Welford, 2013; Peterson, 2007; Whittington, 2012) refer to various principles in CW which are based on the principles initially defined by Hellinger et al. (1998). These principles are defined as follows and have 
been supported by other authors and facilitators (Constellations Group, 2013; Green, 2008; Hellinger et al., 1998):

1. The equal and unequivocal right to belong to a family system

If family members act loyally towards an excluded family member, family wholeness is restored and balanced. However, this is often at the cost of the person acting loyally towards the excluded person (Constellations Group, 2013; Hellinger et al., 1998).

2. The unconscious group conscience that influences guilt and innocence to protect the survival of the group

Guilt and merit belong with whoever has earned it (Green, 2008). Family conscience, including innocence and guilt, balance and order of the family (first before second order), and bonding 'in the service of life' need to be accepted (Hellinger et al., 1998). Several authors highlight hidden symmetries in families (Green, 2008; Peterson, 2007) such as assumptions that 'everybody needs honouring and finding the right place within the system' (Green, 2008). Understanding of the system dynamics on a deeper level can be explored through CW and should be acknowledged as reality (Constellations Group, 2013). Three levels of conscience are acknowledged, which include personal, family, and 'great soul'; following the 'archetypical rules of nature'; and operating to balance a system (Constellations Group, 2013). Connected to the idea of archetypical rules of nature is the principle of $\mathrm{CW}$ that the one who comes later takes from those who came earlier and that the order of precedence needs to be honoured (Green, 2008).

3. The giving of the parents and the receiving of the children

One basic principle agreed upon by $\mathrm{CW}$ facilitators is the assumption that transgenerational family system patterns exist. Based on Hellinger et al. (1998) and emphasised by other scholars is the principle of hierarchies in CW: there is a hierarchy between parents and children, whereby parents give and children take. This giving and taking need to be in a balance and in equilibrium (Green, 2008). Several CW facilitators emphasise that issues in families can be represented by family members within the family and in CW group processes by members of the group. The representation of issues is often experienced through body sensations, thoughts, images, or feelings (Peterson, 2007). Healing can be achieved through movement of representatives in the field and thereby simultaneously within the 'soul of the client' (Constellations Group, 2013). Cohen (2006, p. 230) identifies recurring principles in CW, such as soul, conscience, belonging, balance and hierarchy, and existence. ${ }^{2} \mathrm{CW}$ has been applied to a variety of conditions, for example, symptoms, psychiatric disorders, disability, infertility, victimisation, perpetration of war crimes, fostering, adoption, and couple problems (Ruppert, 2000; Weber, 1994). It has been mentioned that certain sets of systemic principles block learning and prevent the creation of sustainable solutions (Birkenkrahe, 2008). These systemic blockages occur, for example, in a case where a person in a family system is excluded or the principles described above have not been acknowledged by the members of the system. Through representation and resonance phenomena within the represented system, such blockages can be brought into consciousness. This will gain importance for human communication in CW. 


\section{Resonances in CW}

The resonance phenomenon (Sheldrake, Hellinger, \& Schützenberger, 1999) in CW is described as a basic human need (Bauer, 2008). Resonances are vibrations and consist of sympathetic collective or interpersonal vibration and individual vibration. Collective and individual vibrations are interlinked and can be perceived and experienced by individuals and groups. The collective vibration is a response to individual vibration skills and resonance that is built up through individual autonomy and collective belonging (Petzold, 2011) and expressed in natural vibration of a person or other object. Individuals resonate physically, mentally, and spiritually within contextual systems based on ability, need, and skill to adjust contextually to build sympathetic vibrations (Mayer, 2015). Collective and individual vibrations resonate on physiological, psychological, and spiritual levels and can be measured in brainwave synchronicities (Podirsky \& Würtenberger, 2011). This means that if a person resonates with another person, the resonances of these persons can be measured. Usually, individuals who are on the same wavelength resonate well, while individuals who do not share similar wavelengths do not resonate well (Podirsky \& Würtenberger, 2011). However, resonances can also be created through similar actions, thoughts, or feelings. Varga von Kibéd (2000) defines the resonance phenomenon as representative perception, a form of perception that impacts other forms of perception and assumes that a person acquires the knowledge of the system as soon as he or she represents or becomes part of it. System knowledge is experienced and expressed in physical perceptions and reactions (Hellinger, 2001; Sparrer, 1999) and is understood as 'intuitive' (Podirsky \& Würtenberger, 2011, p. 258). Mahr (2003) defines the anticipation of resonance phenomena as 'knowing fields', and Sheldrake (2001) describes them as 'morphogenic resonance'. Morphogenetic resonance is similar to electromagnetic fields, is built upon a given structure and order, reaches beyond space and time, has a cumulative memory, is hybridising, and expands in cooperation with other systems (Sheldrake, 2001). This 'memory' might be based on the collective consciousness, according to Jung (1995), Mahr (2003), and Sheldrake (2001). Knowing fields are, however, dynamic (Mahr,2001), and soul fields (Mahr, 2003) are spontaneous (Latka, 2011), bringing unconscious knowledge into consciousness (Mahr, 2003). The fields are experienced through the senses, while being connected to the collective unconscious (Jung, 1995) and the individual's intuition (Mayer, 2015;Podirsky \& Würtenberger, 2011). Intuition is viewed as a form of knowledge which mediates between the conscious and the unconscious (Sadler-Smith \& Shefy, 2004). It is defined as an in-depth perception which connects cognition and emotion and which is described by Simon (1996) as 'acts of recognition' (p. 89). These intuitive acts of recognition can occur on an intra- psychological level, between the conscious and the unconscious, and also on a transpersonal level, referring to a transpersonal intuition which refers to phenomena based on the collective conscious (Mayer, 2015). Through intuitive recognition, solutions and resolutions can be (re)constructed in CW. Podirsky and Würtenberger (2011) emphasise that intuition is based in a space between conscious and unconscious, but can be recognised and perceived only when the individual explores this space - as in $\mathrm{CW}$ - with a positive emotional mindset, such as with a loving and passionate attitude (Podirsky \& Würtenberger, 2011).

\section{CW and shamanism}

Resonance phenomena in CW have been interlinked with shamanism (Van Kampenhout, 2003, p. 30), highlighting similarities in healing through space, shamanic rituals, sudden change, the influence of spirits, and the impact of spiritual principles. Shamanism refers to spiritual traditions and practices of ethnic groups in Siberia, Mongolia, Lapland, Alaska, and Canada (Van Kampenhout, 2003, p. 17). In Western cultures, it is often used 'to describe not a form, but a content: it now means having a conscious relationship with the spirits' (Van Kampenhout, 2003, p. 
19). Resonances which generally occur in CW are defined as 'natural' healing sources in Shoshone culture that are described as 'indigenous fields' (Mason Boring, 2004). In Shoshone culture, these resonance fields are usually accessed through meditation, prayer, a connection with the ancestors, singing, and healing ceremonies (Mason Boring, 2004). In CW, these resonances are usually accessed through the group process and the constellating of individuals and themes which are represented by individuals within a system. The issues which are connected to resonance phenomena in $\mathrm{CW}$, such as the soul and spirituality, have hardly been connected to it but deserve more attention from a scientific per- spective (Weng, 1997).

\section{Purpose and aims of the study}

Few Southern African scientific empirical, conceptual, and/or theoretical studies refer to CW and facilitators in South Africa (Mayer, 2014). CW has also not been explored with regard to understanding its principles and shamanic interlinkages. The aim of this article is to explore $\mathrm{CW}$ principles and resonance phenomena and the interlinkages with shamanism from the emic perspectives of a South African $\mathrm{CW}$ facilitator. This article therefore responds to four research questions which are aligned with the aims of the study: 'Which principles of CW do firstgeneration CW facilitators apply?' 'What are the interpretations of constellation phenomena happening in CW?' 'How are constellations and shamanism interlinked?' and 'What is the future of CW in South Africa?'

\section{Method}

\section{Research paradigm}

This research draws on the phenomenological and interpretative paradigms (Collis \& Hussey, 2003), including the epistemological tradition of constructivism and interpretive hermeneutics (McManus Holroyd, 2007). It is relativist, transactional, and subjectivist (Guba \& Lincoln, 1998), emphasising the non-objective truth and the application of diverse constructed interpretations (Berger \& Luckmann, 2000). It is a product of interactions and individual thoughts which the researcher reconstructs by producing an impression of the world as he or she sees it (Ratner, 2008).

\section{Participants}

The first CW facilitators in South Africa were trained for 2 years from 2005 onwards and graduated in 2006. The Systems Constellations Association of South Africa (SCASA) was founded, which aims at creating quality standards, principles, ethics in CW, and networks (SCASA, 2013). Firstgeneration constellators were contacted through a snowball sampling process. Six facilitators agreed to participate. Participation criteria were as follows: being first-generation $\mathrm{CW}$ facilitators, being actively involved in the field since 2005, and being South African. All CW facilitators were female, five White and one African, ${ }^{3}$ with different mother tongues: one German, three English, one Afrikaans, and one Zulu speaking.

\section{Instruments}

Data were collected through semi-structured interviews, including seven open-ended questions. The interviews were conducted in English as three of the interviewees were English mother tongue speakers. The other three participants, who indicated German, Afrikaans, and Zulu as mother tongue, were very efficient in English due to growing up bi- or multiculturally, with English as their second language and as the language at school and/or in their institutions of higher education. All of the interviewees had learned CW in courses conducted in English and had also facilitated workshops in English. 
The interviews focused on theory and practice in CW and included questions such as the following: 'Please explain the principles of CW from your viewpoint as a CW facilitator in South Africa', Which connection do you see between CW and shamanism?', or 'Give examples of "typical" topics in constellation sessions in South Africa'. The interview questions did not need further explanation. The interviewees were aware of the principles of CW and familiar with the topics and phenomena referred to, as all of them had had formal training with literature studies and were therefore aware of theoretical concepts emphasised by Hellinger (2001) and Cohen (2006). Observation of facilitators in CW workshops in South Africa from 2010 to 2013 had been done by one researcher. Field notes were taken and a researcher's diary was kept. Data obtained from observations were used to formulate interview questions, gain deeper knowledge on CW in South Africa as expressed by different constellation facilitators, and interpret the data in this study. Triangulation of data, theory, and methods was applied.

\section{Procedure}

Interviewees were invited to participate in the interview on $\mathrm{CW}$ and express their emic perspectives on the topic.

\section{Ethical considerations}

Ethical considerations include respect afforded to and rights of the interviewee, creation of informed consent, confidentiality, anonymity, and transparency (Powell, Fitzgerald, Taylor, \& Graham, 2012). Ethical approval was obtained from the European University Viadrina, Frankfurt (Oder), Germany.

\section{Data analysis}

The in-depth understanding of the emic perspectives of the CW facilitators was created by 'thick descriptions' (Geertz, 1987) of the interview narrations and the analysis of data according to levels of text reconstruction (Ricoeur, 1979, p. 253): the interviewee perceives, experiences, and creates $\mathrm{CW}$; the interviewee reflects and narrates $\mathrm{CW}$ (pre-selection of information); the researcher analyses and interprets narrations on $\mathrm{CW}$; and the researcher presents the re-categorised findings on CW.

Data were analysed using the five-step process of content analysis (Terre Blanche, Durrheim, \& Painter, 2006, pp. 322-326): familiarisation and immersion - the researchers familiarised themselves with the gathered data and read through them with various foci and by integrating observations made during workshops; inducing themes - general themes in the data were defined, such as constellation principles, shamanism, or the future of $\mathrm{CW}$; coding - categories and codes were inductively developed out of the data by identifying similarities and differences in the collected data; elaboration - categories and codes were further elaborated to understand and reconstruct the data; and interpretation and checking to ensure data quality - data were reconstructed and interpreted and set in a more complex context. Data were furthermore reconstructed through intra- and inter-individual validation processes of the researcher and the researched (Yin, 2002, p. 45). Various reflections on the data and discussions were part of the intraand inter-validation processes of the researchers involved.

\section{Results}

An overview of the responses of the facilitators is provided through summaries and quotations, particularly for responses given by more than three facilitators. 



\section{Principles of CW}

Important principles of $\mathrm{CW}$ that five $\mathrm{CW}$ facilitators emphasised are understanding family constellations, intergenerational healing, and dynamics of individual and social family systems. Understanding CW refers to understanding family context and 'order', and why the specific family order developed. It relates to understanding the individual's 'soul' in family context, as well as the family soul (I5) ${ }^{4}$ such as emotions, guilt, harmony, and balance within the family, the collective consciousness, and subconsciousness. The second principle is the intergenerational healing process in which the $\mathrm{CW}$ facilitator connects the client with ancestors and their (life) story (I2, I3), brings ancestors into consciousness (I1), and increases harmony with parents and ancestors, thereby creating well-being in the family system (I5). Intergenerational healing is seen as 'Ubuntu', which includes social values, networking, and identity creation (I2). While creating new, 'healthy forms of family constellations', CW contributes to intergenerational healing through finding a 'good place' in the family for all family members (I5). The third principle of CW (I1-I5) is understanding individual dynamics and the social family system by including fulfilling family roles (I1), the attempt of individuals to get into the strongest family position possible (I3), finding a healthy place (I5), and searching for family members who were forgotten, excluded, or segregated (I2, I4). Interviewee I1 emphasised,

... the child can reach out to the parent again, and take their place as children so that it is possible to turn and face their own life. By making the loyalties visible, and bringing the client into a place where they can move easier between their roles as child to their parents, and adults in their own life (through coming into presence in the here and now rather than living in the family story), the client can turn and face their own life.

Interviewee I1 referred to the 'reaching out' movement between children and parents and finding their place within the family system. Loyalties between family members are shown and 'being present' is created, enabling the individual to change roles (e.g., from child to adult). Principles of $\mathrm{CW}$ include the need for belonging (I2, I3, I4, I5) and representational perception (I1, I2, I3, I4). Three interviewees each mentioned family loyalties, coming into presence, client- centredness (connecting to client resources, life, impeccability), system thinking, identity exploration, and selfdevelopment through therapeutic work as principles of CW. Interviewee I1 observed,

Constellations provide a possibility to get into the strongest position with our families, and are good complements to other forms of self-development and therapy, but not a replacement for them.

Two interviewees, I2 and I6, referred to the connection to a higher power as a fundamental principle in CW. I2 highlighted spirituality from an African perspective by mentioning two Zulu concepts: Mvelingquangi (the creator) and Simakade (the higher power). For I2, the creator was one of the basic principles of resonance phenomena. Constellation was, however, interpreted not only as a principle of resonance phenomena but also as a spiritual or even religious phenomenon. I6 emphasised that higher powers form a basis of $\mathrm{CW}$ and referred to constellations as a spiritual phenomenon which can be realised through meditation, mindfulness, and the integration of Eastern and Western philosophies. Both interviewees interpreted CW in the context of spirituality from both their individual base of understanding and their cultural and religious background. Each of the following principles was referred to by only one interviewee: explore family issues, fits in with Zulu rituals, system of conscience, orders of love, systems methodology, unity and joy, creativity, conscious questioning/listening, efficacy, intentionality, principle of non-interference and movement, self-consciousness, African cosmology principles, and African healing traditions and spiritual mystery school traditions/mystics. Interviewee I2 referred to the relationship between the living and the dead and relating human beings to a higher power. African traditions carry strong positive and healing energies which are interlinked with belonging across generations and various spiritual layers as universal elements. 
One interviewee indicated that $\mathrm{CW}$ is connected to exploring family issues (I2). From her perspective, $\mathrm{CW}$ can be conducted in Zulu cultural contexts due to the fact that $\mathrm{CW}$ as a group process with ritual characteristics generally fits into Zulu ceremonies (I2). Also emphasised in the data were Hellinger's (2001) and Payne's (2005) terms 'system of conscience' and 'orders of love' (I4), system methodology, principles of non-interference and movement, African cosmology and healing traditions, as well as spiritual mystery school traditions and mystics (I6). One interviewee (I6) pointed out that particularly mystics and mystery school traditions form the basis of CW and need to be under- stood. Other principles such as unity and joy, creativity, efficacy, intentionality, selfconsciousness, and conscious questioning and listening also played a role for I6 and are part of the CW processes.

\section{Interpretation of CW phenomena}

Three interviewees (I1, I3, I4) mentioned client-centredness and process-orientation as basics. Interviewee I 2 explained why client-centredness is important:

Because there are such diverse cultures and religions in South Africa, and also represented in constellations workshops, I try to not explain this phenomenon to the participants, but rather ask them to fit it into a frame of reference that makes sense to them.

Interviewee $\mathrm{I} 2$ did not provide ideas on $\mathrm{CW}$ but noted that she allows participants to find their own interpretation of constellation phenomenology. She ensures that the interpretation resonates with the client's ideas and belief systems. She saw CW as frame for a shared human experience which interlinks individuals as human beings across cultures. Three $\mathrm{CW}$ facilitators highlighted the 'phenomenon of consciousness' and the 'collective consciousness' of Jung (1995) (I1, I3, I5). Interviewees I1, I3, and I6 used the concept of field theories by referring to 'quantum theories' and 'morphogenetic theories' as well as the theories of the 'knowing field' and 'phenomenological field'. I3 explained,

The closest explanation I can refer to is that of the quantum field - quantum physics and the morphogenic field which has been discovered by Rupert Sheldrake: 'Morphogenic fields are created by the patterns of physical forms. They help guide the formation of later similar systems where a newly forming system "tunes into" a previous system by having within it a "seed" that resonates with a similar seed in the earlier form'.

For I3, the theory of $\mathrm{CW}$ was related to the explanation of morphogenetic fields and resonance phenomena, as for I4, who emphasised awareness and sensitivity regarding resonance. Two interviewees (I5, I6) spoke about the soul, about the awareness of body sensations, and about resonance in a physical sense as a way of experiencing body sensations in CW. Only one interviewee in each case drew a connection to the following: psychodynamic theory (I4), transpersonal epigenetics (I4), shared human experiences (I1), spiritual electricity (I6), transference and countertransference (I6), intuition (I6), empathy (I6), and compassion (I6). I6 provided psychological interpretations of transference, countertransference, psyche, empathy, and compassion. Here, CW practices are based on profound theoretical knowledge and deep reflection.

\section{CW and shamanism}

In terms of the possible interconnectedness of CW and shamanism, I3 and I5 felt that these include a spiritual practice, using field information, drumming and meditation, and working with ancestral energy and the dead. Interviewee I3 referred to the healing powers of constellation:

$\mathrm{CW}$ is a healing process that consists of both spiritual and physical elements. They both involve the use of the entire body for information. It is common in many tribal cultures as a way of life. Some constellators 
use drumming and meditation to bring in the energy of ancestors into the constellation space. While I3 saw spirituality as the base for both $\mathrm{CW}$ and shamanism, all interviewees found at least one concept, value, or practice that overlaps in $\mathrm{CW}$ and shamanism. I1 interlinked $\mathrm{CW}$ and shamanism with values of dignity, reverence, seating order, and 'soul retrieval', which are part of identity integration processes. I6 connected CW to mystic teaching and esoteric circles, while I4 highlighted respect for the wider system's wisdom, sense-making of symptoms, system-specific communication, and dreams. For I5, working across time and space and finding peace and solutions are major themes in $\mathrm{CW}$ and shamanism:

In a way $\mathrm{CW}$ is shamanic work. We work with dead people, and beyond time and space. The ancestors seem to have the need to be heard and acknowledged and when there is a good resolution their representatives (by implication: they) seem to be at peace.

I1 concluded that certain values and practices of shamanism are the foundation of CW: Important concepts that form the foundation of constellations such as dignity, reverence, and seating orders can be found in Southern African traditions. A colleague of mine once said it beautifully: constellations are African traditions made digestible to the West.

I1 felt that $\mathrm{CW}$ is based on shamanic practices and is a way to make it digestible to the West. CW is regarded as a combined practice based on traditional and postmodern knowledge of psychology. The interviewee believed that resonance phenomena as they occur in $\mathrm{CW}$ are also part of shamanic practices. CW is a practice that has been developed in the West, but it integrates shamanic knowledge into the practice in a way that is accepted in African as well as in Western set- tings. The interviewee referred in her statement to the acceptability of CW across cultures, integrating basic universal knowledge into a specific cultural setting.

\section{The future of CW in South Africa}

Five facilitators (I1, I3, I4, I5, I6) saw CW as a generational and cross-cultural learning opportunity that will flourish in future. Representing another person - across cultures, gender, and generations helps one to experience diversity, different perspectives, understanding 'the other', exploring deeper wisdom, and 'creating balance in systems'. CW was seen as an effective individual healing intervention tool in combination with other therapeutic interventions that impact the collective consciousness in healing wounds left by apartheid and feelings of guilt (I1, I3, I5). I4 foresaw a future for $\mathrm{CW}$ in South African business-related contexts. Parallel to the positive CW future, facilitators identified potential hindrances, such as its negative perception in public, being labelled as 'demonic', 'magical', 'esoteric', or 'Antichrist' (I1, I4, I5). Publications are needed to increase the overall acceptance of $\mathrm{CW}$ (I5, I6) and to present scientific explanations on $\mathrm{CW}$ phenomena.

\section{Recommendations of South African CW facilitators}

Facilitators aimed at integrating $\mathrm{CW}$ with various healing approaches (I2, I5) and promoted $\mathrm{CW}$ as an intervention method that celebrates the new South Africa while working with the collective consciousness (I3). SCASA plans to develop CW standards and expand its influence on national and international levels.

\section{Discussion}

Findings show that South African CW facilitators referred to $\mathrm{CW}$ as a therapeutic healing process, drawing on phenomenology and ancestral belief as described by Cohen (2006). As in Europe (Stiefel et al., 2002), CW has gained interest on a practical level within South African contexts. Regarding the theoretical background of phenomena occurring in $\mathrm{CW}$, facilitators mentioned 
resonance (Sheldrake et al., 1999), human communication, knowledge, intuition, and representative perception (Podirsky \& Würtenberger, 2011), as well as representative perception in the col- lective experience of CW (Petzold, 2011). CW facilitators also referred to shared human experiences such as individual autonomy and collective belonging (Petzold, 2011). Body sensations were high- lighted as resonating with others on physiological, psychological, and spiritual levels (Podirsky \& Würtenberger, 2011). Facilitators were aware of the theoretical foundation of CW, emphasised by Varga von Kibéd (2002) as 'representative perception', as the experience of resonance in physical perceptions (Hellinger, 2001; Sparrer, 1999), as intuition (Podirsky \& Würtenberger, 2011, p. 258), and as 'knowing fields' (Mahr, 2003), morphogenic resonance (Sheldrake, 2001), consciousness and collective unconsciousness (Jung, 1995), quantum physics (Podirsky \& Würtenberger, 2011), and fields of the soul (Mahr, 2003). Most facilitators saw $\mathrm{CW}$ as a universally practised method connected to shamanic healing, as emphasised by Payne (2005) and Van Kampenhout (2003), and used for trauma healing (Levine, 2005). Facilitators viewed CW and shamanistic practices as connected through spirituality, which Van Kampenhout (2003) describes as a conscious relationship with the spirits. Parallels were seen in the literature and from the facilitator's viewpoint in soul retrieval and system-specific communication (Mason Boring, 2003; Payne, 2005). South African facilitators highlighted an understanding of family constellation, intergenerational healing, as well as dynamics of the individual and the social family system by reproducing the orders of love (Hellinger et al., 1998). Peterson (2007) mentions body sensations, representational perception, and loyalties, which were also emphasised in the interviews. The Constellations Group (2013) has defined several principles of $\mathrm{CW}$ which were also mentioned by the $\mathrm{CW}$ facilitators. South African facilitators added the connection to a higher power, as well as concepts of creativity, efficacy, unity, and joy as basic principles which are currently not mentioned in the literature. A variety of principles were mentioned which relate to the ideas of Western concepts (e.g., Hellinger et al., 1998; Payne, 2005; Van Kampenhout, 2003), as well as to the CW facilitator's individual belief systems.

Regarding themes in CW, the soul, conscience, belonging, balance, hierarchy, and existence were mentioned, as referred to by Cohen (2006). Illness, symptoms, victimisation, perpetration, fostering, adoption, and couple problems (Ruppert, 2000; Weber, 1994) were regarded as important themes in South African constellations. CW is conducted and is acknowledged in organisational contexts, as emphasised by Birkenkrahe (2008) and Stiefel et al. (2002). Despite major changes in South Africa, inequalities exist in South African CW in relation to race, gender, and other diversity categories (Chugh \& Brief, 2008; Lyubomirsky, 2013). Internationalising apartheid (Mayer, 2005) is perceived in CW in terms of change in the identity formations of members of certain cultural and ethnic groups, the impact of perpetrator and victim definitions, and definitions of self and others. The fragmentations and controversial identity constructions and the struggle with the past (Mayer \& Viviers, 2014b) are recognised in CW. Facilitators emphasised that CW contributes to collective healing and agreed with Steyn (2001) that it is time to tackle the issues in South Africa. CW can be an 'add-on' to other healing processes (Allen \& Allen, 2000; Leildé, 2008; Lund, 2003) such as community work (Gobodo-Madikizela, 2002) and trauma debriefing (Allen \& Allen, 2000). The majority of facilitators saw CW as a chance to reconcile Western and traditional approaches, which corresponds with Moodley and West's (2005) finding that traditional and psychotherapeutical combined approaches are promoted. Concepts of perpetration and victimisation were reviewed (Swartz,1996) and combined in traditional and nontraditional healing concepts (Berg, 2003), as in CW. South Africans across cultures consult traditional healers for healing (Ross, 2007) and attend constellation workshops, as highlighted by Mason Boring (2004), Van Kampenhout (2003, 2008), and Payne (2005). Facilitators contributed to combining the context-specific knowledge of African and Western healing wisdom. The study provides insights into CW facilitators' views on selected topics of CW in South Africa. This study comes with limitations. The research is founded on a small set of data, and the number of participants is limited to six and biased in terms of gender (only female respondents agreed to 
participate) and culture (five out of six participants are South African of European descent). Furthermore, the research methodology is based on qualitative research methods only. The findings are subjective in nature and reflect the views of selected individuals. Findings are not necessarily generalisable.

\section{Conclusion}

The main aim of this article was to explore CW principles and resonance phenomena and the interlinkages with shamanism from the emic perspectives of South African CW facilitators. CW facilitators referred to the same principles and similar themes as in the international literature. Themes of CW in South Africa are bound to cultural and historic experiences of members of certain groups. CW facilitators were open to integrating $\mathrm{CW}$ with other therapeutic interventions and spiritual practices to support healing as a transgenerational and cross-cultural intervention. If mindfully adjusted, sensitively implemented, and combined with other therapeutical practices, $\mathrm{CW}$ was seen as an effective intervention method in the South African context. It is recommended that more qualitative, quantitative, and mixed-method studies be used to explore CW across cultures and within organisations. Empirical research on $\mathrm{CW}$ principles, as well as on $\mathrm{CW}$ comparisons to other cultural healing processes, should be conducted and synergies should be explored. South African $\mathrm{CW}$ facilitators should share their context-specific knowledge on national and international levels and contribute to spreading indigenous knowledge combined with $\mathrm{CW}$ practices internationally.

\section{Acknowledgements}

We would like to acknowledge and thank the South African constellation work (CW) facilitators who participated in this research.

\section{Funding}

This research received no specific grant from any funding agency in the public, commercial, or not-for-profit sectors.

\section{Notes}

1. For a detailed explanation of the constellation work (CW) processes see, for example, Cohen (2004).

2. In CW, Hellinger (2001) speaks of constellation principles rather than of concepts. Cohen (2006), and other authors therefore refer to the terminology of principles, which might also include terms such as 'soul' which might elsewhere be defined as concepts.

3. Defined according to the Employment Equity Act (Department of Labour, 1998): White (European descent) and African (African descent, previously in apartheid described as Black). However, the term 'Black' is often still used in contemporary South Africa to describe individuals of African origin. The terms the $\mathrm{CW}$ facilitators used in the interview were kept in the findings section of the study.

4. I5 means interviewee number 5 . 


\section{References}

Allen, A., \& Allen, M. M. (2000). The South African truth and reconciliation commission as a therapeutic tool. Behavioural Sciences \& the Law, 18, 459-477.

Bauer, J. (2008). Prinzip Menschlichkeit. Warum wir von Natur aus kooperieren. (The humanity principle. Why we cooperate naturally). München, Germany: Heyne Verlag.

Berg, A. (2003). Ancestor reverence and mental health in South Africa. Transcultural Psychiatry, 40, 194207.

Berger, P. L., \& Luckmann, T. (2000). Die gesellschaftliche Konstruktion der Wirklichkeit. Eine Theorie der Wissenssoziologie (17th ed.). (The societal construction of reality). Frankfurt, Germany: Fischer.

Birkenkrahe, M. (2008). System constellations as tool supporting organisational learning and change processes. International Journal of Learning and Change, 3, 125-144.

Chugh, D., \& Brief, A. P. (2008). Introduction: Where the sweet spot is: Study diversity in organizations. In A. P. Brief (Ed.), Diversity at work (pp. 1-2). New York, NY: Cambridge University Press.

Cohen, D. B. (2004). Bert Hellinger's family constellation method and its place in the psychotherapeutic tradition (Master's thesis). Saybrook Graduate School and Research Center, San Francisco, CA.

Cohen, D. B. (2006). 'Family constellations': An innovative systemic phenomenological group process from Germany. The Family Journal: Counseling and Therapy for Couples and Families, 14, 226-233.

Cohen, D. B. (2008). Systemic family constellations and the use with prisoners serving long-term sentences for murder or rape (Doctoral thesis). Saybrook Graduate School and Research Center, San Franscisco, CA.

Collis, J., \& Hussey, R. (2003). Business research: A practical guide for undergraduate and postgraduate students (2nd ed.). Basingstoke, UK: Palgrave Macmillan.

Constellations Group. (2013). Family constellations: Basic principles and ideas. Retrieved from http://www. theconstellationsgroup.com/articles/basic_principles.html

De la Rey, C., \& Owens, I. (1998). Perceptions of psychosocial healing and the Truth and Reconciliation Commission in South Africa. Peace and Conflict: Journal of Peace Psychology, 4, 257-270. Department of Labour. (1998). Employment Equity Act, No. 55 of 1998. Pretoria: South African Department of Labour. Available from http://www.labour.gov.za

Geertz, C. (1987). Dichte Beschreibung. Beiträge zum Verstehen kultureller Systeme. (Thick descriptions. Papers to understand cultural systems). Frankfurt, Germany: Suhrkamp.

Georgiadou, S. (2012). Participants' experiences in Hellinger's Family Constellation work: A grounded theory study (Doctoral thesis, University of Lousiana at Monroe). Retrieved from http://search.proquest. com/docview/1172852673

Gobodo-Madikizela, P. (2002). Remorse, forgiveness, and rehumanization: Stories from South Africa. Journal of Humanistic Psychology, 42(1), 7-32.

Green, S. (2008). Creating organisational flow: Using Hellinger constellation work for unblocking the past. Retrieved from http://www.ochre.ie/Creating\%20Organisational\%20Flow\%5B1\%5D.pdf

Guba, E. G., \& Lincoln, Y. S. (1998). Competing paradigms in qualitative research. In N. K. Denzin \& Y. S. Lincoln (Eds.), The landscape of qualitative research: Theories and issues (pp. 195-220). Thousand Oaks, CA: SAGE. 
Hellinger, B. (2001). Love's own truths. Phoenix, AZ: Zeig, Tucker \& Theisen.

Hellinger, B., Weber, G., \& Beaumont, H. (1998). Love's hidden symmetry: What makes love work in relationships. Phoenix, AZ: Zeig, Tucker \& Theisen.

Hunger, C., Bornhäuser, A., Link, L., Schweitzer, J., \& Weinhold, J. (2014). Improving experience in personal social systems through family constellation seminars: Results of a randomized controlled trial. Family Process, 53, 288-306.

Jung, K. G. (1995). Aion. Gesammelte Werke Band 9/2. Beiträge zur Symbolik des Selbst. (Collected texts, 9/2. Texts on the symbols of the self.) Düsseldorf, Germany: Walter Verlag.

Latka, T. (2011). Feld. In C. Reutlinger, C. Fritsche, \& E. Lingg (Eds.), Raumwissenschaftliche Basics. Eine Einführung für die Soziale Arbeit. (Space Science Basics. An Introduction to Social Work.) Wiesbaden, Germany: Springer.

Leildé, A. C. (2008). Changing identities in urban South Africa: An interpretation of narratives in Cape Town (Doctoral thesis, University of Stellenbosch, Stellenbosch, South Africa).

Levine, P. A. (2005). Healing trauma: Restoring the wisdom to your body. Louisville, CO: Sounds True.

Livotov, P. (2007, November). Integration of method of systemic constellations into moderated educational and problem solving workshops with TRIZ for technical and non-technical tasks. Paper presented at the TRIZ-Future Conference, Frankfurt/Main, Germany.

Lund, G. (2003). 'Healing the nation': Medicolonial discourse and the state of emergency from apartheid to truth and reconciliation. Cultural Critique, 54, 88-119.

Lynch, J. E., \& Tucker, S. (Eds.). (2005). Messengers of healing: The family constellations of Bert Hellinger through the eyes of a new generation of practitioners. Phoenix, AZ: Zeig, Tucker \& Theisen.

Lyubomirsky, S. (2013). The myth of happiness: What should make you happy but doesn't, what shouldn't make you happy but does, what happiness really is - And isn't. New York, NY: Penguin.

Mahr, A. (2001). Die Offenheit des wissenden Feldes. Von personalen zu transpersonalen) Erfahrungen in Aufstellungen. In G. Weber (Ed.), Derselbe Wind lässt Drachen steigen. Systemische Lösungen im Einklang (pp. 166-179). (The same wind makes kites fly. Systemic solutions in harmony.) Heidelberg, Germany: Carl-Auer Systeme.

Mahr, A. (2003). Konfliktfelder - Wissende Felder. Systemaufstellungen in der Friedens- und Versöhnungsarbeit. (Fields of conflict - knowing fields. Systemic constellations in peace and reconciliation work.) Heidelberg, Germany: Carl-Auer System.

Mason Boring, F. (2003, April/May). The presence and essence of indigenous field in family and human systems constellation. Paper presented at the International Congress for Family \& Human Systems Constellations, Würzburg, Germany.

Mason Boring, F. (2004). Feather medicine: Walking in Shoshone dreamtime: A family system constellation. Fort Lauderdale, FL: Llumina Press.

Mason Boring, F., \& Sloan, K. E. (Eds.). (2013). Returning to membership in earth community: Systemic constellation with nature. Pagora Springs, CO: Stream of Experience Production.

Mayer, C.-H. (2005). Mauern aus Glas. Südafrikanische Narrationen zu Differenz, Konflikt und Identität. (Artificial walls. Narrations on difference, conflict and identity.) Münster, Germany: Waxmann. 
Mayer, C.-H. (2015). Intuition als Gesundheitsressource im Kontext systemischer Resonanz. Intuition as a health resource in the context of systemic resonance. In C.-H. Mayer \& S. Hausner (Eds.), Salutogene Aufstellungen? Beiträge zur Gesundheitsförderung in der systemischen Aufstellungsarbeit (pp. 66-94). (Salutogenic constellations? Texts on health promotion in systemic constellation work.) Göttingen, Germany: Vandenhoeck \& Ruprecht.

Mayer, C.-H., \& Hausner, S. (Eds.). (2015). Salutogene Aufstellungen? Beiträge zur Gesundheitsförderung in der systemischen Aufstellungsarbeit. (Salutogenic constellations? Texts on health promotion in systemic constellation work.) Göttingen, Germany: Vandenhoeck \& Ruprecht.

Mayer, C.-H., \& Viviers, A. (2014a). 'Following the word of God': Empirical insights into managerial perceptions on spirituality, culture and health. In C.-H. Mayer \& D. Geldenhuys (Eds.), Spirituality, culture and health in management. Special issue of International Review of Psychiatry (Vol. 26, Issue 3, pp. 302-314).

Mayer, C.-H., \& Viviers, A. (2014b). 'I still believe': Reconstructing spirituality, culture and mental health across cultural divides. In C.-H. Mayer \& D. Geldenhuys (Eds.), Spirituality, culture and health in management. Special issue of International Review of Psychiatry, 26, 265-278.

Mayer, C.-H., \& Viviers, A. (in press). Exploring cultural issues for constellation work in South Africa. Australian and New Zealand Journal of Family Therapy.

McManus Holroyd, A. E. (2007). Interpretative hermeneutic phenomenology: Clarifying understanding. The Indo-Pacific Journal of Phenomenology, 7(2), 1-12.

McQuillin, J., \& Welford, E. (2013). How many people are gathered here? Group work and family constellation theory. Transactional Analysis Journal, 43, 352-365.

Moodley, R., \& West, W. (2005). Integrating traditional healing practices into counselling and psychotherapy. Thousand Oaks, CA: SAGE.

Mpofu, E., Peltzer, K., \& Bojuwoye, O. (2011). Indigenous healing practices in Sub-Saharan Africa. In E. Mpofu (Ed.), Counseling people of African ancestry (pp. 3-21). Cambridge, UK: Cambridge University Press.

Payne, J. L. (2005). The healing of individuals, families and nations. Forres, Scotland: Findhorn Press.

Peterson, J. (2005). Some heretical thoughts on organizational constellations. In J. E. Lynch \& S. Tucker (Eds.), Messengers of healing. Phoenix, AZ: Zeig, Tucker \& Theisen.

Peterson, J. (2007). Systems theories and systemic constellations. Portland, OR: Human Systems Institute.

Petzold, T. D. (2011). Kommunikation: Kreativ und gesundheitsorientiert. (Communication: Creative and health oriented.) In T. D. Petzold \& N. Lehmann (Eds.), Kommunikation mit Zukunft-Salutogenese und

Resonanz (pp. 9-26). Future-oriented communication - salutogenesis and resonance. Bad Gandersheim, Germany: Verlag Gesunde Entwicklung.

Peyton, S. (2015). Three strands of healing: The interpersonal neurobiology of constellation work. Bernried Morning Talk No. 1, May 2014. The Knowing Field: International Constellations Journal, 25, 14-20.

Podirsky, K., \& Würtenberger, B. (2011). Quantensprung. Die Spiritualität der Wissenschaft entfaltet sich. Information, Resonanz, Bewusst-Sein. (Quantum leap. The spirituality of science develops. Information, Resonance, Consiousness.) Berlin, Germany: Berliner Wissenschafts-Verlag. 
Powell, M. A., Fitzgerald, R. M., Taylor, N., \& Graham, A. (2012). International literature review. Ethical issues in undertaking research with children and young people. Dunedin, New Zealand: Center for Research on Children and Families.

Ratner, C. (2008). Cultural psychology and qualitative methodology: Scientific and political considerations. Culture \& Psychology, 41(2), 1-34.

Ricoeur, P. (1979). Der Text als Modell: Hermeneutisches Verstehen. (The text as a model: Hermeneutical understanding.) In W. L. Bruehl (Ed.), Verstehende Soziologie. Grundzuege und Entwicklungstendenzen. (Understanding sociology. Basics and development tendencies.) (pp. 109-132). München, Germany: Nymphenburger Verlag.

Roevens, J. L. M. (2008). Systemic constellations work in organizations (Doctoral thesis, Tilburg University, Tilburg, Netherlands). Retrieved from https://pure.uvt.nl/portal/files/1039955/9789051796162_content. pdf

Rogers, D. E. (2010, March). The role of place in personal and systemic transformation. Project presented for the Master of Arts in Organizational Systems, Saybrook University, Sydney, Australia.

Ross, E. (2007). Traditional healing in South Africa: Ethical implications for social work. Social Work in Health Care, 46, 15-33.

Ruppert, F. (2000). Familiengeheimnisse und Psychosen - verrückt machende Suche nach Auswegen aus Verwirrungen im Familiensystem. (Family secrets and psychosis - searching for solutions in the family system.) Praxis der Systemaufstellung, 2, 33-43.

Sadler-Smith, E., \& Shefy, E. (2004). The intuitive executive: Understanding and applying 'gut feel' in decision-making. Academy of Management Executive, 18(4), 76-91.

Schusterman, D. (2003). Sign language of the soul: A handbook for healing. Falls Church, VA: Writer's Collective.

Sheldrake, R. (2001). Chaos, creativity and cosmic consciousness. Rochester, VT: Park Street Press. Sheldrake, R., Hellinger, B., \& Schützenberger, A. A. (1999). Reviewing assumptions: A dialogue about phenomena that challenge our world-view. Heidelberg, Germany: Carl-Auer-Systeme Verlag.

Simon, H. A. (1996). The sciences of the artificial (3rd ed.). Cambridge, MA: The MIT Press.

Sparrer, I. (1999). Heilsame Rituale und systemische Resonanz. (Healing rituals and systemic resonance.) In W. Scheiblich (Ed.), Bilder, Symbole, Rituale. (Images, symbols, rituals.) (pp. 137-165) Freiburg im Breisgau, Germany: Lamberus.

Steyn, M. E. (2001). Whiteness just isn't what it used to be: White identity in a changing South Africa. New York: State University of New York.

Stiefel, I., Harris, P., \& Zollmann, A. W. F. (2002). Family constellation: A therapy beyond words. Australian and New Zealand Journal of Family Therapy, 23, 38-44.

Stresius, K. (2006). Wissenschaftliche Untersuchungen zur Aufstellungsarbeit - der Forschungs(gegen)stand (Scientific studies on constellation work - the topic and state of research.) Praxis der Systemaufstellung, 9, 90-93.

Swartz, L. (1996). Culture and mental health in the rainbow nation: Transcultural psychiatry in a changing South Africa. Transcultural Psychiatry, 33, 119-136.

Systems Constellations Association of South Africa. (2013). Available from http://family constellations. co.zal 
Terre Blanche, M. T., Durrheim, K., \& Painter, D. (2006). Research in practice. Applied methods for the social sciences. Cape Town, South Africa: University of Cape Town Press.

Van Kampenhout, D. (2003). Images of the soul: The workings of the soul in shamanic rituals and family constellations. Phoenix, AZ: Zeig, Tucker \& Theisen.

Van Kampenhout, D. (2008). Die Heilung kommt von außerhalb. Schamanismus und Familien-Stellen (3rd Edition). (Healing is coming from external sources. Shamanism and constellation work.) Heidelberg, Germany: Carl Auer Verlag.

Varga von Kibéd, M. (2000). Bemerkungen über philosophische Grundlagen und methodische

Voraussetzungen der systemischen Aufstellungsarbeit. (Philosophical foundations and methodological basics of systemic constellation work.) In G. Weber (Ed.), Praxis des Familien-Stellens. Beiträge zu sys- temischen Lösungen nach Bert Hellinger (3rd Edition, pp. 51-60). (Practice in constellation work. Texts on systemic solutions by Bert Hellinger.) Heidelberg, Germany: Carl-Auer-Systeme.

Varga von Kibéd, M. (2002). Unterschiede und tiefere Gemeinsamkeiten der Aufstellungsarbeit mit Organisationen und der systemischen Familienaufstellungen. (Differences and deep similarities in constellation work and systemic family constellations.) In G. Weber (Ed.), Praxis der Organisationsaufstellungen. Grundlagen, Prinzipien, Anwendungsbereiche. Reihe: Werkstattschriften zu systemischen Lösungen nach Bert Hellinger (2nd Edition, pp. 11-33). Heidelberg, Germany: Carl- AuerSysteme.

Weber, G. (1994). Zweierlei Glück. (Double standard luck.) Heidelberg, Germany: Carl Auer.

Weng, C.-Y. (1997). An initial exploration to the group psychological effect of Taiwan family systemic constellations (Master's thesis). Retrieved from http://libserver2.nhu.edu.tw/ETD-db/ETD-search-c/ view_etd? URN=etd-0119109-112300

Whittington, J. (2012). Systemic coaching and constellations: An introduction to the principles, practices and application. Philadelphia, PA: Kogan Page.

Yin, R. K. (2002). Case study research: Design and methods. London, England: SAGE.

Young, S. (2004). Narrative and healing in the hearings of the South African Truth and Reconciliation Commission. Biography, 27(1), 145-162. 